\title{
The Three Pillars of Sustainability Framework: Approaches for Laws and Governance
}

\author{
William Henry Clune ${ }^{1}$, Alexander J. B. Zehnder ${ }^{2}$ \\ ${ }^{1}$ Asian School of the Environment, Nanyang Technological University, Singapore \\ ${ }^{2}$ Board of Trustees, Nanyang Technological University, Singapore \\ Email:whclune@gmail.com
}

How to cite this paper: Clune, W.H. and Zehnder, A.J.B. (2018) The Three Pillars of Sustainability Framework: Approaches for Laws and Governance. Journal of Environmental Protection, 9, 211-240. https://doi.org/10.4236/jep.2018.93015

Received: January 11, 2018

Accepted: March 20, 2018

Published: March 23, 2018

Copyright (c) 2018 by authors and Scientific Research Publishing Inc. This work is licensed under the Creative Commons Attribution-NonCommercial International License (CC BY-NC 4.0). http://creativecommons.org/licenses/by-nc/4.0/ (c) (1) (8) Open Access

\begin{abstract}
The three pillars of sustainability framework is a multidisciplinary implementation and solutions oriented approach that recognizes most successful and scalable sustainability solutions require the presence of, and are driven by, all three pillars simultaneously: 1) technology and innovation; 2) laws and governance; and 3) economics and financial incentives. The three pillars framework is strategic because it often reveals or describes specific and feasible changes that advance sustainability solutions within markets and institutional settings. The section on technology discusses the crucial role that technology plays in creating new ways for doing more in our rapidly urbanizing communities by using less resources and energy inputs. The section on economics discusses problems with current conceptions of economic welfare that measure growth (flow) rather than the asset base (wealth), and explores possibilities for integrated and multidisciplinary analysis for coupled economic and social systems. The section on laws and governance considers the role of legal frameworks related to incentives, regulatory baselines, and in public policy formation, including influences and feedback effects from social norms, changing culture, and sustainability education. Technological development and engaging economic markets are at the center of our best and most rapidly deployable sustainability solutions. In that context, a specific focus is given throughout the discussion sections to the key role of laws and governance in supporting relevant, effective, and sustainable technological and economic development, as well as to highlight the crucial (often final) steps the law plays in successfully implementing new sustainability projects. As the discussions and examples (taken from Asia, the US, and Europe) demonstrate, the three pillars framework is flexible and useful in a number of contexts, as a solutions template, as an integrated planning approach, as a decision making guide, and
\end{abstract}


for determining project priorities.

\section{Keywords}

Sustainability, Law, Governance, Model

\section{Introduction}

The three pillars of sustainability framework is a multidisciplinary and solutions oriented approach for sustainable development based upon the key and connected roles of: 1) technology and innovation; 2) laws and governance; and 3) economics and financial incentives. ${ }^{1}$ The three pillars framework is solutions oriented because nearly all sustainability projects that are successful and scalable are driven by all three pillars simultaneously. The three pillars will be analyzed separately in this paper, with a particular focus on approaches and applications related to laws and governance. At the same time, and recognizing the ways in applied situations that the pillars are connected and interrelated, several examples are introduced. While much of the discussion considers connections and incentives related to and among markets, preferences, behavior, and other large scale semi-autonomous systems, the three pillars framework is strategic because it often reveals or describes specific and feasible changes to drive sustainability solutions within markets and institutional settings.

The section on technology discusses the crucial role that technology plays in creating methods of doing more with less, which is particularly relevant in the context of cities and rapid, global urbanization. One example is phosphate reduction in laundry soap. After many years of regulatory activity and industrial cooperation, which produced modest changes, a breakthrough technology emerged that offered a satisfactory substitute for phosphorous, and led to rapid adoption. The section also notes the interrelationship of technology, economics, and law that is suggested by the example.

The section on economics discusses problems with current conceptions of economic welfare that measure growth (flow) rather than the asset base (or wealth) upon which growth depends. Failing to account for welfare in the future can be seen in the example regarding coastal flooding and the enormous costs that will be incurred in many of the world's most populous cities. As an example of a solution, and one which allows for better accounting, a German law subsidized its domestic renewable energy industry by sharing costs with upstream and downstream market participants. This example also demonstrates the need for many small and simultaneous changes, due to the difficulty of wholesale ${ }^{1}$ The three pillars of sustainability model was developed by Professor Alexander J.B. Zehnder at Nanyang Technology University (NTU) in Singapore in 2011, where it has been used as an organizing idea and planning template for research and applied projects; for example, the NTU Singapore Sustainability Symposium (S3), an annual international platform started in 2014 for sustainability thought leadership, and that provides early input to Singapore's World Cities Summit and Mayor's Forum, bases its sessions and content development around the three pillars model. 
change. This section discusses the role of multidisciplinary analysis and planning in developing steps for changes in economy, technology, demography, and politics, citing Singapore's Coastal Protection Framework as an example.

The section on laws and governance considers the role of legal frameworks in supporting sustainability solutions. One example is San Diego's support for green building projects, e.g., through zoning and permitting. The city also created long term planning mechanisms for considering such matters as balancing green building and public safety, and engaging local stakeholders. Another example is Singapore's BCA Skylab, which develops energy efficient building technologies, and considers law and governance issues as part of this development process. Public policies can also influence environmental values, education, and social norms thereby helping to relax previously hard political and social constraints. Multidisciplinary education and research can encourage well considered political negotiations, laws, and agreements.

All of this must be considered within the context that sustainability outcomes key to human survival and quality of life on this planet are now compressed within a relatively short time frame and policy implementation window. What happens 100 years from now is largely irrelevant to the worst case scenarios of ecological crises we will create and face over the next 50 years. Everything depends on the rapid implementation and scaling up of effective sustainability solutions. This, in turn, depends on integrating sustainability practices and decision-making into most of society's regular business, institutions, laws, and practices.

Technological development and engaging economic markets are at the center of our best and most rapidly deployable solution possibilities. Laws and governance are simultaneously important components to support technological and economic development, and crucial (often final) steps in themselves for successfully implementing sustainability solutions. But it's crucial, regardless of which pillars or levers we rely on for solutions, that our sustainability goals must everywhere include efficacy and speed.

Therefore, if we're to be successful, there will need to be deep changes that embed sustainability objectives within our institutional, cultural, and market activities that reach the whole range of human activities and environmental impacts. As the discussion and examples that follow will demonstrate, the three pillars framework is useful in this regard in a number of ways: as a solutions and strategy template; for designing specific and applied solutions that are more likely to be successfully implemented and scalable; as an integrated planning and policy approach; as a decision guide for analyzing and determining priority projects; and, as a problem identification framework.

\section{The Three Pillars of Sustainability}

The three pillars for applied and solutions oriented sustainable development are: 1) technology and innovation; 2) laws and governance; and 3) economics and financial incentives. Compared to other important sustainability models that 
have come before, such as the triple bottom line framework, the three pillars of sustainability model moves from a conceptual framework to an implementation and action framework. The triple bottom line defined sustainability's potential and its primary objectives. Sustainability combines the creation of a feasible and livable space for human society within our environmental protection and ecological conservation goals. The economic component correctly acknowledges that all of our environmental and sustainability challenges are directly connected to economic production and consumption, and need to be considered alongside the other objectives (Figure 1).

By comparison, the three pillars framework anchors the most crucial components for the implementation of sustainability solutions and applied projects, and therefore also helps identify crucial break points. In this way, and across a wide variety of planning, policy, and project applications, the three pillars model is a strategic and action oriented framework for achieving the successful implementation of sustainability solutions (Figure 2).

The three pillars model, along with the various applications and examples introduced in this paper, is a simplification of a complex, multidisciplinary, and systems oriented set of challenges and opportunities related to sustainable development. But the framework still provides an effective structure and analytic rigor related to key points of support and contribution. This is important for multidisciplinary work and projects. Our ultimate goal is to optimize global and social sustainability goals, even if (or especially when) contributions and roles from individual disciplines or stakeholders need to be sub-optimized or scaled back in order to achieve broader social and global objectives.

The three pillars framework is simultaneously an approach to embed sustainability goals and considerations into the fabric of more of our social objectives and institutional processes. And it's a way of making space for the right mix of considerations to successfully implement sustainability solutions at speed and scale. The implications of this approach are immediate and highly impactful for applied and project-level applications, and it's equally supportive for informing decision-making and balancing priorities at various public policy, law-making, and governance levels.

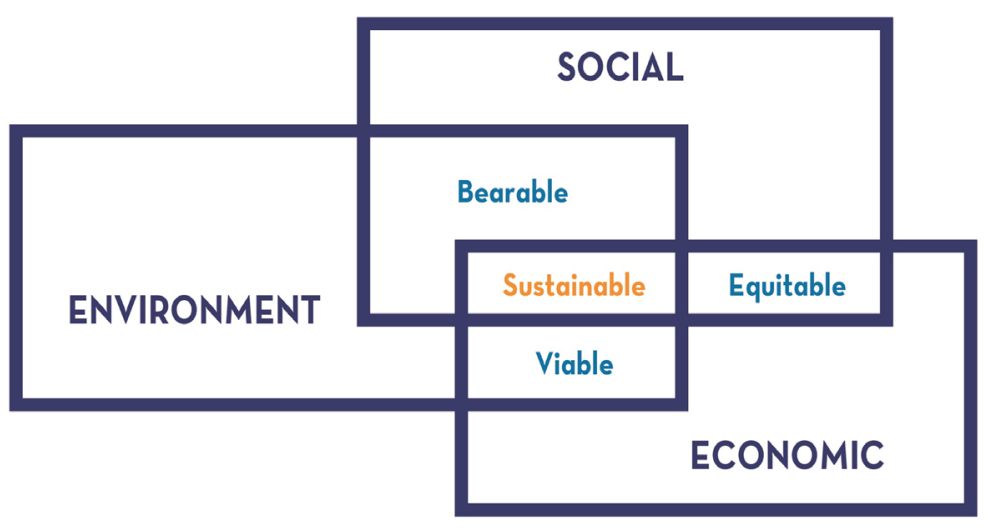

Figure 1. The triple bottom line framework. 


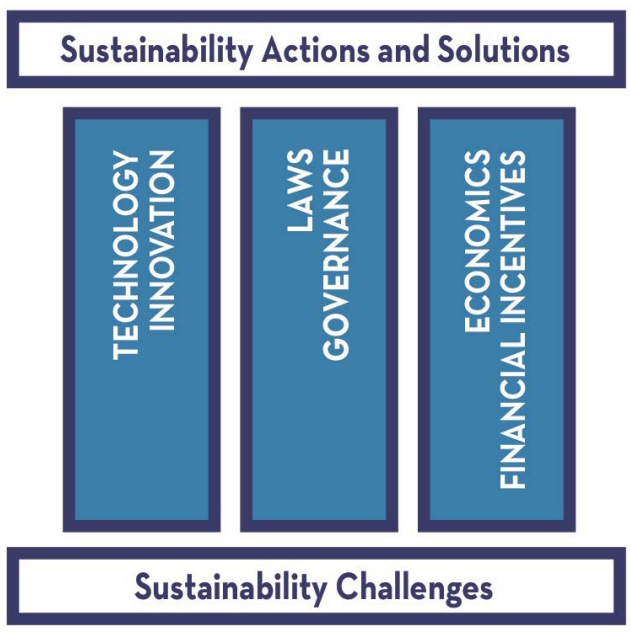

Figure 2. The three pillars of sustainability, a strategy framework for sustainability solutions.

\subsection{Technology and Innovation}

Technology and innovation, in engineering and product development, but also with respect to management structures and entrepreneurship, will continue to be key to our overall sustainability strategy. Doing more with less is often a question best addressed by technological solutions. Technology can ease hard constraints of ecological limits, and simultaneously relieve political and economic pressures (thereby allowing space and opportunity for more sustainability solutions from all quarters). And sustainability solutions typically fail, even in the presence of the other pillars, when feasible and culturally appropriate technologies are not available.

Example 1. Eutrophication, phosphorus, zeolites, and laundry detergents in the United States.

In the US in the mid-1960s, a primary cause of rivers and lakes turning green and having an abundance of aquatic plant growth (eutrophication) was high levels of phosphorus (a major nutrient source for plants) in the water. One of the main sources of effluent phosphorus was phosphates in laundry detergents. At about the same time, the scientific community started studying this eutrophication process and problem, with the National Academy of Sciences (NAS) and National Research Council (NRC) creating a planning committee in response to growing public concern and protests. An international symposium was held on the subject at the University of Wisconsin in June 1967, and was sponsored by the US Atomic Energy Commission, the US Department of Interior, and the US Department of the Navy. One key outcome of this symposium was a recommendation to reduce phosphorus in wastewater by developing non-phosphate detergents [1].

The public also became very active at local, state, and federal levels in these discussions during the 1960s and 1970s. As a result, local and state governments (including Michigan, New York, and Florida) began drafting or enacting phosphate legislation. At the federal level, both the Environmental Protection Agency (EPA) and Federal Trade Commission (FTC) began investigating and drafting guidance on the eutrophication problem caused by phosphates in laundry soaps [1]. 
At the same time, the private sector was also involved and supportive of making a change. The three largest laundry detergent manufacturers (Procter \& Gamble, Lever Brothers, and Colgate-Palmolive, with $80 \%$ of the US market) were cooperative in negotiating for a solution that would keep an economically level playing field for all suppliers. In 1970, H.J. Morgens, president of Proctor \& Gamble, said: "We recognize that the public wants phosphates out of laundry detergents and we intend to take them out. Our job is to make certain that we remove them as rapidly as we can do in a thoroughly reasonable manner. This we are doing [1]".

While reductions of phosphates in laundry soap began in the US during the 1960s and early 1970s, including limited bans in some localities and areas, the elimination was incomplete or slowed by the fact there was no good substitute for phosphorus. It was only in the 1970s that zeolites (as a new technology, whose discovery was in part driven by political pressure and economic opportunity) were introduced in the US as substitutes in laundry soap. It was at this point that phosphorus was phased out of the US market rapidly and through the 1980s. Today, one of the main commercial applications of zeolites (or similar substitutes) is for the commercial manufacture of laundry detergents [2].

When one of the key pillars of sustainability is missing, effective solutions and implementation are hindered. In this case, both the economic (including consumer and corporate stakeholder support) and law (including enthusiastic civic engagement) pillars were present, but not until the technological solution developed was a breakthrough possible. At which point, with all three pillars engaged, implementation and a solution rapidly followed.

Actually, it's rarely a question of technology as separate from economics or law, but one of how the three develop together to mutually support social goals for sustainable development and required solutions to given challenges or obstacles (again, at the speed and scale required). In fact, any discussions about technology immediately highlight the interconnectedness between technology, economic development, and legal frameworks (including regulatory baselines and governance issues). In other words, we are also considering how legal institutions and economic incentives can better support the creation and deployment of new technological solutions.

For example, government fiscal policies (funding for research, and state support for technology implementation where there are market failures), regulatory baselines (which create new demand for technological solutions, or may be technology forcing), and legal frameworks (competition law, and intellectual property rights) can also be viewed in broader terms of how they support sustainable development. Actually, our broader policies and frameworks already operate to determine pathways of technology and innovation development. For example, it's difficult to envision a broadly-based global transition to a low carbon economy with internationally pervasive subsidies of fossil fuel production, agricultural food-based biofuels, and centralized (or monopoly) energy demand and distribution units.

Just as importantly, and related to the integrated nature of technology development and deployment, it's incorrect to say that we already have enough technology available in the world: the culturally appropriate and economically feasible technologies are often questions as specific as the locations and applications 
in which they are needed. These are questions, in the first instance, of technology being defined by specific economic, political, legal, historical, and cultural realities. And it speaks to the need to continuously develop new, and adapt existing, solution-specific, time-specific, and culture-specific technologies.

\subsection{Economics and Financial Incentives}

Economic growth and consumption trajectories in the manner we have previously (and historically) achieved them have exceeded the planet's ecological capacity. If we said this conclusion, as well as existing economic production frontiers, is predicated upon current technology levels, it misses the point that our technology-economic-governance systems are completely integrated. The three pillars strategic framework can help put some of these constraints and challenges, as well as possible solutions and decision-making approaches, into focus. Importantly, we're not giving up on welfare, the three pillars approach looks for a feasible, solutions-oriented path where we have both increases in welfare and sustainability. This is accomplished by embedding our consideration and understanding of ecological-human-social systems more deeply into our decision-making and institutional processes.

Unsustainable economic development may pose no immediate threat to many people's standard of living, or even carrying on with business as usual for a time. However, our natural and ecological deficit spending is now clearly identified. Too many of these environmental costs are not being fully accounted for by social and economic institutions and actors, while being fully accounted for by the planet's ecosystem. Sooner rather than later, the mounting planetary and ecological debts are going to be paid. The largest scale example of this is human made climate change, and the (now) inevitable and massive exposure risks and adaptation costs that nations and cities over the whole world will pay in the decades to come (Figure 3).

Importantly, we also have to be flexible in addressing these global issues, because we don't yet know the answers to all our sustainability challenges. Within fast-moving technology fields (that constantly re-define our best economic and market possibilities), and within naturally complex economic systems, markets, and dynamic cultural responses, we're now adding a requirement for speedy solutions (including the ability to quickly retire ideas that don't work). In this sense, an approach like the three pillars framework provides the essential structural elements (feasibility in technology, law, and economics) that all of our sustainability solutions require. At the same time, it applies while still allowing us to configure or order these essential elements to suit specific projects, changes, and time periods. In this approach, as much as to any specific project application, the three pillars strategy framework speaks to an important planning and guidance role for laws and governance.

But here, we're faced (as a global community) with a number of difficult economic trade-offs and decisions going forward, partly rooted in the fact that economic development has been (and will continue to be) a beneficial engine for 


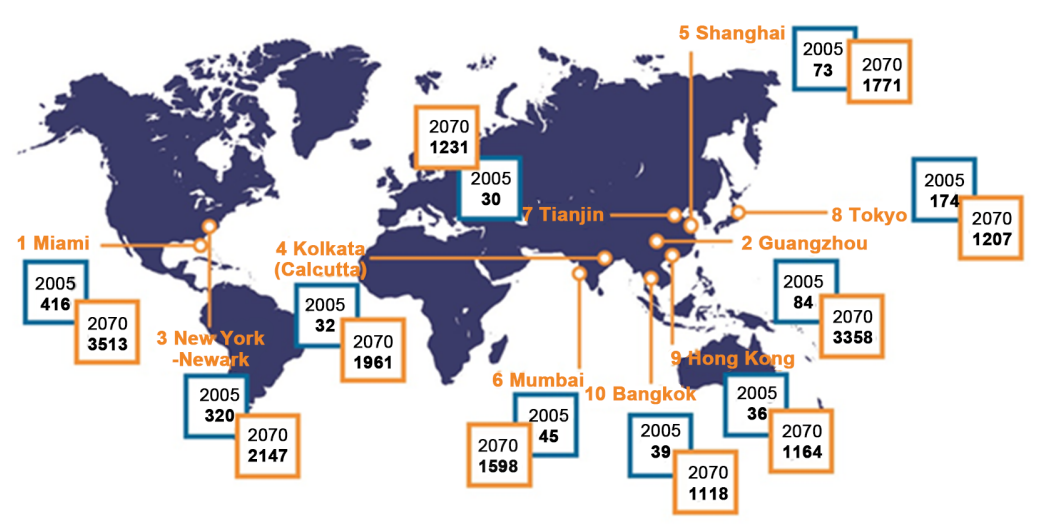

Source: OECD Graphic:Allianz Global Corporate \& Speciality.

Figure 3. Top 10 cities ranked by assets exposure to coastal flooding in the 2070 s (\$USbn).

human development (which has lifted billions of people out of poverty and into lives of opportunity and dignity over the past 50 years). And within this context, planetary ecological stresses are certain to increase, even with new technological developments.

While a rapidly growing global middle class is a positive development in terms of reducing poverty, and in terms of creating deep and diversified economic markets, the challenges to balancing our global ecological accounting are substantial for a planet facing the prospect of adding another one to two billion developed-economy consumers within the next 20 to 30 years. At the same time, it's important to remind ourselves that developed world consumers and businesses (in North America, Japan, and Europe, but also including parts of the Middle East and Asia like the Gulf States, Singapore, and Taiwan) annually consume multiples (on a per capita basis) of energy and natural resources compared to consumption in developing and emerging economies.

As such, and going forward, all policies and planning for economic growth must more fully include considerations of planetary and ecological integrity and capacity [3]. Human survival, economic opportunity, and prosperity have always been connected to ecological survival and integrity, whether or not we've properly acknowledged or accounted for this fact. Research that frames questions of ecological and environmental pressures as questions of economic development and growth is persuasive. It draws direct links between growth (in terms of human populations and related output) and global environmental effects. This is, on the one hand, a question of international law, multilateral cooperation, and global governance, as a way to address ongoing, massive market failures that include: the serial mispricing of risks; endemic global distortions of important price signals for food, water, and energy; our inability to overcome collective ac- 
tion problems to support agreements on sustainable development and resource use; and the exportation of pollution externalities due to the transboundary nature of many environmental challenges.

The consequence of poor (local, regional, and global) accounting is that economic outcomes are continually overstated. If we focus exclusively on the flow (growth) without sufficient consideration of the asset base (wealth) on which that flow ultimately depends, it leads to unsustainability and all its long-term negative impacts. One application here for the three pillars of sustainability framework is to support international law and global governance in: 1) its balancing of priorities (for example, economic versus environmental goals); 2) making decisions based upon the likelihood of successful implementation of a given sustainability-related activity; and, 3) addressing known market failures, particularly where we see that a successful sustainability solution would likely follow once all three pillars are in place.

Example 2. State support of renewable energy in Germany, as balanced against EU internal market protections.

In the Preussen Elektra case, the European Court of Justice (CJEU) upheld a German law requiring power suppliers to purchase electricity from in-state producers of renewable energy at above-market prices, the extra costs of which were to be shared among upstream and downstream energy market participants. The CJEU argued that EU environmental objectives were now sufficient to support (and balance) this kind of state environmental program against internal market protections, including free economic movement interests, even considering the fact that the law was clearly economically discriminatory in mandating purchases from in-state suppliers [4].

In addition, the Preussen Elektra Court argued the German law did not create an illegal state aid situation because there were a number of private undertakings involved in sharing the costs of these in-state energy purchases. This part of the ruling is not entirely persuasive with respect to avoiding EU state aid prohibitions, because, for starters, it ignores an independent form of economic discrimination that has been created: specifically, using state resources to favor in-state undertakings does burden out-of-state businesses trying to compete in the same market on equal terms. The power suppliers in this case included some private undertakings, but also included suppliers owned partially or wholly by the state. As such, Germany was subsidizing a substantial part of its own renewable energy mandates to buy locally.

In this example, the CJEU developed supporting language, if not exactly lasting legal precepts or deeper precedents, deciding in favor of Germany's support of its developing, domestic renewable energy markets (including energy producers). The three pillars framework could provide in similar cases a principled decision guide or more structured justification based on the components key for successful sustainability implementations, and in light of the increasing importance of sustainability objectives in the EU.

For example, a missing pillar (here, sufficiently developed economic markets in renewables, in combination with explicit, implicit, or status quo subsidies of fossil fuel energy production) justifies stronger consideration of local or member state actions supporting environmental and sustainability objectives. In this case, with both the technological and legal supports in place, it can be persuasively argued that the scaling-up and proliferation of renewable energy production was limited only by immature economic markets. Put a different way, national environmental programs aimed at strengthening the missing economic pillar could be given consideration based on probable increases in implemen- 
tation success resulting from putting all three pillars in place.

In the Preussen Elektra case, the underlying justifications for Germany's renewable energy purchase mandates, and its de facto subsidy program, were not discussed at length. But the rationale is clearly related to strengthening or compensating for missing economic depth and market maturity necessary for the long-term success of sustainable energy supply. Without state measures and support, in-state energy providers would not support relatively expensive in-state renewable energy producers (which, for many environmental policy reasons, Germany wanted to support). Also, without the shared compensation scheme, too much of the increased cost burden would fall on one level of the energy supply and distribution market (which Germany believed might be disadvantageous or even disruptive to the continued development of this crucial sector). Even the likely other economic and longer-term objective of German law, to use state subsidies to build a strong and profitable domestic renewable energy industry, is not inconsistent with the evidence-based requirements of a three pillars strategy. Strengthening the economic pillar puts renewable energy on an equal footing as existing and subsidized fossil fuel energy suppliers and infrastructure.

In general, there is nothing self-evident or predetermined about economics that necessitates continual expansion and ecology-destroying growth. Another role for technology (in concert with law, governance, mature economic markets, and financial incentives) is a focus on economic growth through increases in productivity (of every input or factor of production, including labor). And not, by contrast, growth only from an expansion of population and labor supply, and their commensurately increasing infrastructure requirements. Another lever is to take people and many of their basic economic motivations as they are, and to engage the other two pillars (technology and legal frameworks) to achieve better sustainability outcomes.

It's difficult to imagine a wholesale restructuring of economics, markets, or market actors ${ }^{2}$ when preferences and markets also self-organize with or without government organization or approvals [5]. It's true that people and culture can be changed (or nudged) through education and the normalizing effects of law. For example, we can support the creation of a culture of more conservation mindedness by taxing the profligate use of natural and scarce resources. Markets will also engage automatically when we are (eventually, but certainly not ideally) driven by ecological necessity, crisis, or collapse. Here again there may be more immediate sustainability opportunities, ideally going all the way back to research and planning activities, and guided by models like the three pillars to achieve improvements, positive feedback effects, and the nudging of markets and other semi-autonomous systems (Figure 4).

This suggests another set of approaches supported by the three pillars model at local (city), regional, and international levels to help guide and influence sustainability outcomes in an applied, market-based, and solutions-oriented

${ }^{2}$ In fact, ordoliberalism proposes decentralized and competitive economies promote individual liberty in opposition to tendencies towards fascism or dictatorship; individuals controlling and holding their own wealth have power and voice, as opposed to when wealth is held or distributed exclusively by states or kings. EU competition law is fashioned to some extent on the theories of ordoliberalism. 


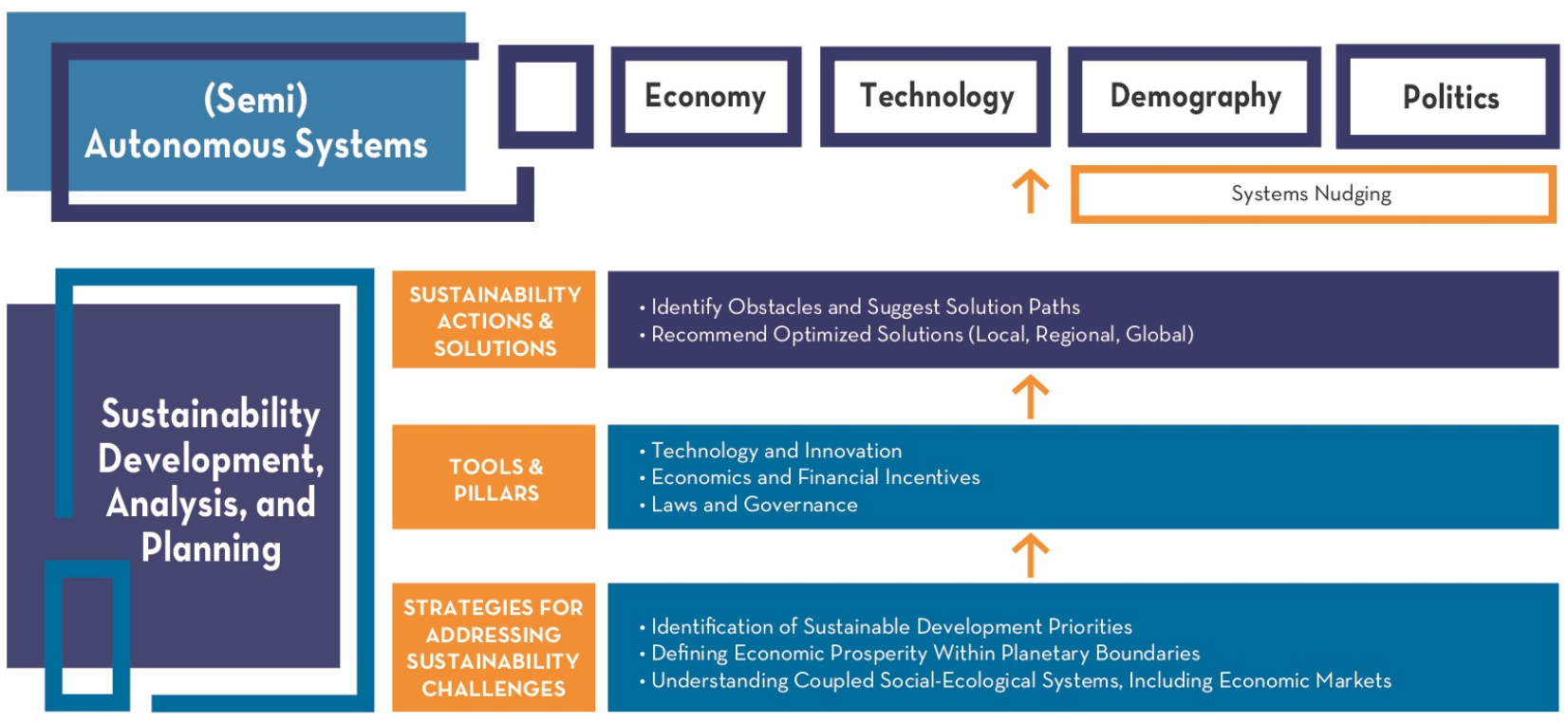

Figure 4. The three pillars framework can help define incentives, levers, and other positive feedback effects to change or nudge markets and other key semi-autonomous system.

manner. In summary, while macro, international, and multilateral approaches will continue, micro or local level solutions are also effective at solving problems and influencing behavior and trends. In fact, market actors everywhere in the world follow a predictable (whether rational or not) set of strategies, based largely upon everyday motivations like survival, getting enough to eat, addressing fear and anxiety, seeking pleasure, and accumulating a buffer of resources to cope with an uncertain future. These terms can be translated to other objectives, such as career success, income smoothing, or profit motive, but the labels aren't important here.

We're not overlooking the important question regarding whether the way corporations, economic agents, and consumers currently interact has itself become a cause and driver of unsustainable (national and global) trajectories of growth, consumption, and pollution. In fact, the connection between the three pillars is made when researchers ask if traditional economic measures like annual GDP growth (which still drives many economic policy decisions) are helpful or even useful indicators of social health, well-being, happiness, human development, or prosperity. As many commentators have noted, innovation and artistic capacities [6], or "know how" in the way existing technologies can be effectively used and combined [7], may be more important to economic success than productive capacity alone. In fact, we are right to question the link between economic success and many standard drivers (including government fiscal and monetary interventions ${ }^{3}$ ) for boosting or focusing on growth [8]. This is relevant to the deeper structure and functioning of economic and technology markets (in

3"Second, and not unrelated to the previous finding, most growth accelerations are not preceded or accompanied by major changes in economic policies, institutional arrangements, political circumstances, or external conditions." See Reference [8]. 
the sense of semi-autonomous systems), and it's certainly a question for policy, law, and planning.

For now, and focusing on more specific examples and interventions, a good example is the particular role of importance in sustainable development for cities, and related to global, accelerating urbanization trends. Cities may be the source of many of our sustainability problems, but they are also among the most diverse, dynamic, and economically efficient places on the planet. In other words, cities are just as likely to produce many of our best sustainability solutions. Technology, thinking in terms of the three pillars strategy framework, will continue to play a key role here. The big issues like clean water, food security, energy supply and delivery, land use, health, and transportation drive daily life on a large scale in cities and metropolitan areas. The connection to law and governance is just as immediate, and is addressed in the next section. Cities, given their value to nations and the world as economic assets, and due to the large number of people that live in urban areas (now a majority of the world's population and soon to be a super-majority), are also on the front lines in terms of exposure to and impact from adaptation and environmental impact challenges. This is now driving a large part of new sustainability and urban adaptation investment in Asia (Figure 5).

\section{The cities contributing most to global GDP by 2030}

Top 15 cities worldwide by GDP in 2030 (in billion GBP) Converted from USD TO GBP on 13 -10-15

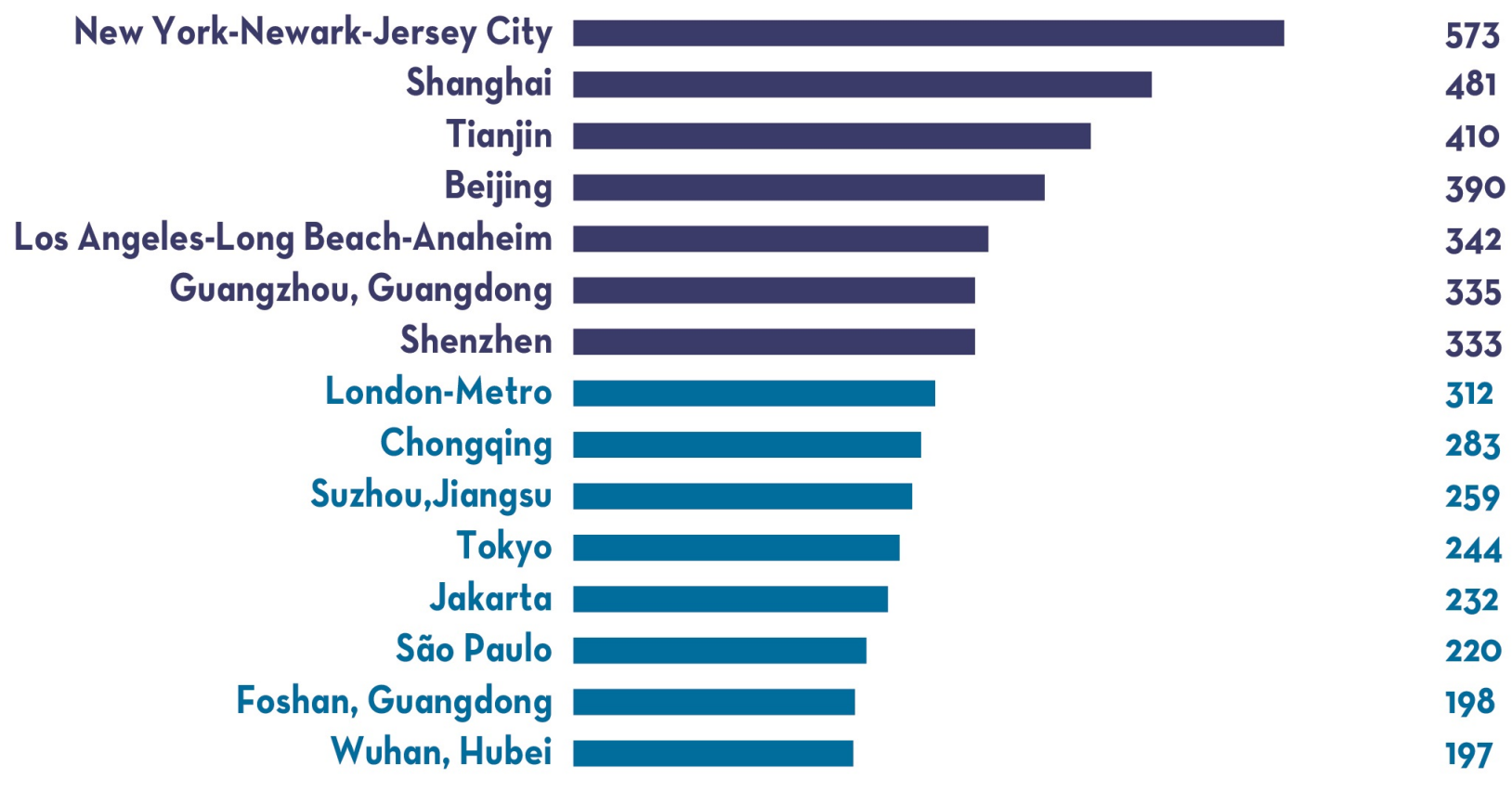

Source: Oxford Economics.

(a) 


\section{Shanghai, China}

In Shanghai, $76 \%$ of the population are below the rise caused by a 4 degree increase in temperatures - some 22.4 million people. Even if we restrict warming to a 2 degree increase, this will still affect 11.6 million people.

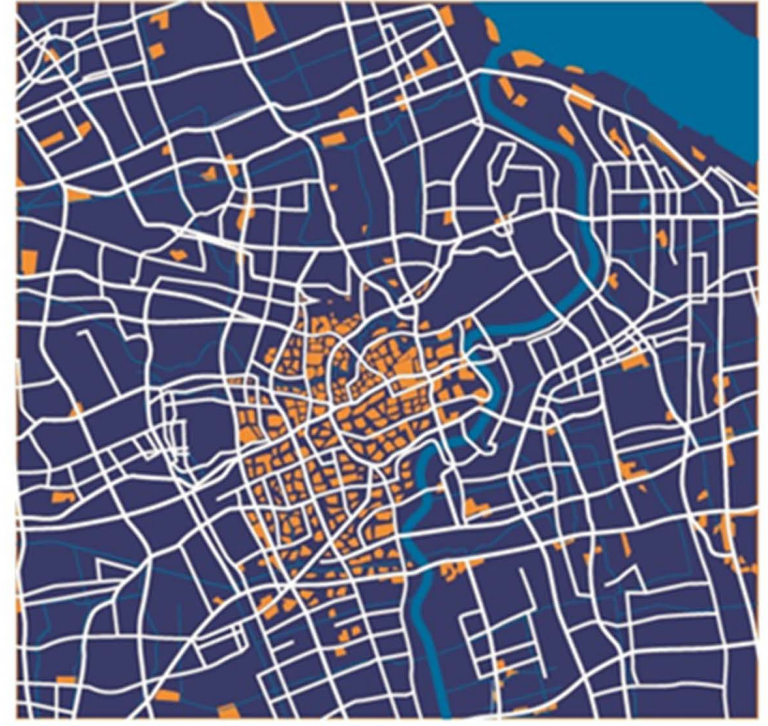

$4^{\circ} \mathrm{C}$ Warming $\left(7.2^{\circ} \mathrm{F}\right)$

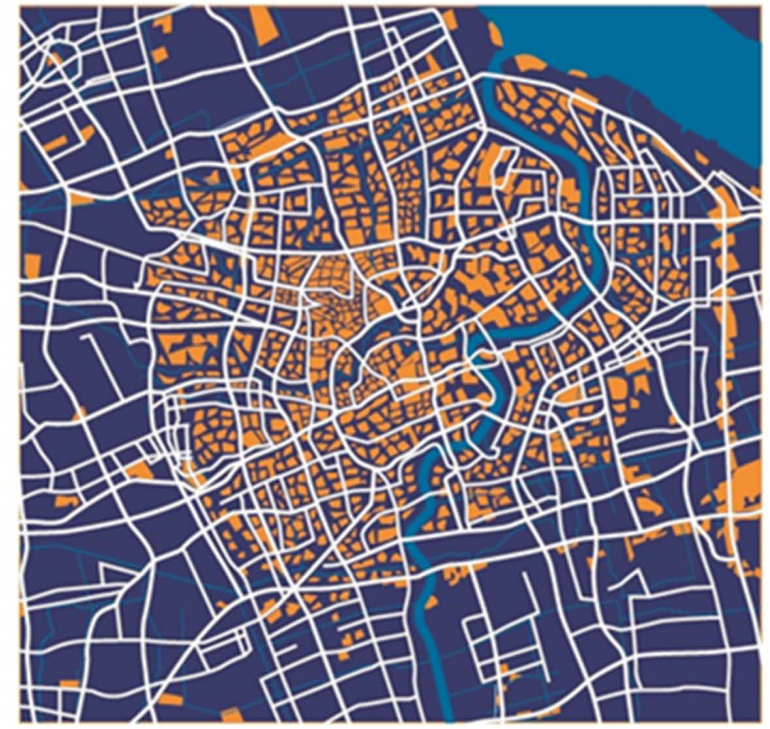

$2^{\circ} \mathrm{C}$ Warming $\left(3.6^{\circ} \mathrm{F}\right)$

area above sea level

area below sea level

\section{Source: Climate Center, World Economic Forum.}

(b)

Figure 5. Global cities and climate change.

In fact, it's possible to see these drivers leading to effective responses in places like Singapore that are undertaking large scale sustainability planning and projects at national, regional, and international levels. The three pillars are present in most of Singapore's successful and influential sustainability efforts, including implementing a carbon $\operatorname{tax}^{4}$ in 2019 [9]. This is clearly about making an opportunity from necessity, while keeping in mind the pressing domestic need for scale and speed of sustainability solutions (which in many cases in Asia also involves starting this work relatively recently and needing to catch up). The presence of all three pillars, as well as stakeholders and market development

\footnotetext{
4"Singapore intends to implement a carbon tax from 2019 as part of its efforts to cut greenhouse emissions, Finance Minister Heng Swee Keat announced in his Budget 2017 speech on Monday (Feb 20). Calling it 'the most economically efficient and fair way' to reduce greenhouse emissions, Mr. Heng said the Government has been studying the option for several years. 'It will create a price signal to incentivise industries to reduce their emissions, complementing the regulatory measures which we are also introducing', he said. Revenue from the carbon tax will help fund measures by industries to reduce emissions. The tax may also spur new opportunities in green growth industries such as clean energy." See Reference [9].
} 
representative of these pillars, also signals a long term business and economic opportunity. There's no doubt whatsoever that demand for solutions to urban, adaptation, and environmental impact challenges will increase significantly in the years to come.

Example 3. Singapore and the coastal protection framework.

A three pillars approach (combining from early stages good governance, ensuring local and global economic opportunities, and developing world class technological solutions) is at the heart of Singapore's sustainability success strategy. Singapore is committed to finding workable sustainability solutions at scale and speed, and integrated national frameworks and strategies are being developed in the context of emerging domestic and global challenges [10].

The fact that there are significant economic opportunities to be had in becoming a global sustainability leader supports Singapore's overall growth objectives, by building an economy that grows by productivity (not only by more people and infrastructure), by innovation and information capacity (rather than more production or manufacturing), and in exporting beneficial sustainability solutions to growing international markets. The economic potential and growing demand (in China, India, ASEAN, and globally) for sustainability products and solutions has allowed Singapore to create opportunities from its own necessity [11].

Singapore has built and supported world class university research in cleantech and sustainability related technologies in renewable energy, green transportation, water and resources management, and environmental health. It has also created many platforms for cutting-edge and collaborative sustainability research and test-bedding (technological, economic, and political) of sustainability solutions. At the same time, the island city-state is an early warning sensor for the world that is emerging, many of the environmental impact challenges and constraints faced here will (sooner rather than later) be confronted elsewhere.

An example of this, and a good example of the application of the three pillars framework in planning for a specific project, is the Singapore Coastal Protection Framework (CPF). The CPF is the nation's adaptation response to global warming, climate change, sea-level rise, and increasing flooding risks. The CPF is a substantial undertaking, involving major technology deployments and infrastructure development: it covers more than $400 \mathrm{~km}$ of total coastline, and includes the construction of marine and coastal barriers, sea walls, wave breaks, and an array of complementary new inland structures and systems relating to flood control and water security. The main risks of climate change and sea level rise for Singapore are flooding and coastal erosion. The scenarios for sea level rise range, as assessed over several possible scenarios under consideration, from 18 $\mathrm{cm}$ to more than $60 \mathrm{~cm}$, over mid to long-term time horizons through 2050 and 2100.

The CPF presents an integrated and continuous range of marine, coastal, inland, and hinterland development projects, likely to touch almost every area of planning, development, and land use in Singapore, both now and into the future. Significantly, sustainable development planning in Singapore now strongly encourages integrated planning efforts [12]. Singapore's ongoing CPF perfectly illustrates the need for a fully integrated design and implementation process: 1) for deploying technology and engineering planning; 2) for considering sustainable economic development, as well as economic opportunities for commercializing technologies and expertise developed during the project; 3 ) for environmental protection and public safety; 4) for the interests of multiple stakeholders, including protecting heritage and cultural sites; 5) and for building institutional capacity, including new laws and governance structures, to support the organization of multi-ministerial, regulatory, and coordinated actions. 
The CPF is a good example of the application of the three pillars strategy framework for sustainability project planning, execution, and implementation.

\subsection{Laws and Governance}

The deep changes necessary to embed sustainability objectives within our institutional, cultural, and market activities must reach the whole range of human activities and environmental impacts. The key role here for law and governance in planning and creating public policy is clear, and the three pillars framework describes a supportive solutions template, an integrated planning approach, a method of analysis, and a problem identification framework. An approach like the three pillars model provides the essential structural elements for many of our sustainability solutions, while allowing us flexibility over projects, technological shifts, and time to re-configure and re-order elements as required.

In fact, within the complex, multidisciplinary, and interconnected sustainability challenge, the most critical and innovative stages are often the implementation of policy making, laws, legislation, regulation, compacts, and agreements. These are often, and in practice, the final steps. But the three pillars framework demonstrates the importance of integrating legal and governance issues into the earliest possible stages of: 1) technology development; 2) setting research agendas; 3) considering economic feasibility and commercialization potential; and 4) for almost all other considerations of public policy that intersect with sustainability.

This approach is similar and related to the fact that sustainability is fundamentally a multidisciplinary endeavor. In parsing sustainability projects between professional areas, accounting for the three pillars is also to identify and connect key disciplines within decision-making, projects, or spheres of influence in which they all can be more effective. Our future sustainability challenges are of such complexity that single disciplines cannot solve them. Dealing, for example, with some of the big issues within a city related to housing, transportation, clean water, energy security, ensuring livability and public order, and providing education, requires a more integrated analysis than ever before. Our timing is critical, such that consideration of the three pillars, and the full range of disciplinary inputs related to these pillars, needs to occur at the beginning of our thought, planning, funding, investment, and constructing processes. And they can no longer be considered as afterthoughts or add-ons.

Laws, governance, and regulations often play important roles that initiate opportunities ahead of the other two sustainability pillars. Technology forcing environmental regulations are a good example of this. For technology and innovation, legislation and policy-making, including but not exclusively related to funding, are also key to supporting vigorous and successful scientific and technology research. Patent and IP law are also good examples of key legal frameworks that provide important incentives to scientists and researchers. Likewise, commercial and competition law remain important to promoting innovation and disruptive business models from which many sustainability opportunities 
(online platforms, minimizing physical travel requirements, sharing economy models, and even alternative currency options) have emerged.

But even when technology development and commercialization potential lead the process, getting the laws and governance in place (permits, zoning, engineering practices, and construction standards to name a few) is still essential for successful sustainability solutions. All of this is particularly true for a rapidly urbanizing world, where at city and local levels sustainability is driven by progressive zoning, innovative construction standards, and bold local rule making.

Speaking more broadly, legal frameworks and a robust regulatory system continue to be crucial at all levels for sustainability to ensure the following: 1) equity and fairness in process; 2) continued and consistent progress; and, 3) to protect public interest projects from being hijacked or aborted. Public opinion and law making also coincide and become mutually reinforcing (or mutually regressive) at many junctions related to the most innovative and cutting edge work. At national, regional, and international levels, sustainability depends upon matching the scope and scale of law and governance to social and ecological contexts, and creating a more connected approach between ecological boundaries, socio-economic drivers, and legal frameworks.

\subsubsection{Supporting the Success of Specific Projects}

The three pillars strategy framework is a pragmatic approach to sustainability, and there are many examples of sustainability solutions with good potential that fail because one of the pillars is missing. The model also indicates key stakeholders and levels of input required because all three pillars need to be engaged (for most projects, and at most scales) for sustainability solutions to be successful and implemented.

Example 4. Sustainable buildings, and local rules and policies, in San Diego.

About $40 \%$ of all energy in the US is consumed by residential and commercial buildings [13]. This potential for conservation and sustainability has been understood for many decades, as demonstrated in the development and availability of many technologies from new materials (lighter and better insulating, or requiring less energy in their manufacture), new construction techniques and processes (like prefab or modular kits), to renewable energy and smart grid applications. There is also no lack of economic feasibility, proven return on investment, or even consumer market demand for green buildings.

One important obstacle identified by researchers and commentators is when there's a lack of city and local rulemaking to support innovative or cutting edge green building projects [14]. Ranging from zoning, permitting, engineering and construction standards, and other (usually legitimate) public safety ordinances, inflexible or not updated local and city laws may themselves prevent good sustainable building projects; or, hinder them with additional time and expense. This is also a straightforward example demonstrating the importance of engaging all three pillars.

Of course, a lot has changed in this area over the last 20 years, and many cities have not only addressed specific gaps by creating new zoning and permitting provisions, but many have successfully leveraged the deeper concept of embedding a more flexible and supportive governance framework into fundamental construction permitting and over- 
sight processes. San Diego (California, US) is a good example. This starts with the city's statement of purpose making building for sustainability a priority, and in order to be responsible on behalf of future generations. They created the Sustainable Building Expedite Program for a permit deviation process to balance support for innovations in green building with public safety standards [15]. They also created the "City of Villages" initiative [16] which engaged public stakeholders in a discussion process outlining and encouraging development best practices like mixed-use commercial and residential projects, car light community planning, and a variety of other sustainable development design priorities.

The immediate implication, of course, is that engagement should come as early as possible in a sustainability project or program. In fact, the earlier the better when integrating or considering the connections between the three pillars, which usually should also include consideration of laws and governance.

Example 5. BCA Skylab in Singapore.

"The BCA SkyLab is a state-of-the-art rotatable test facility pivotal to developing innovative energy efficient building technologies. The facility is modelled after the Lawrence Berkeley National Laboratory's FLEXLAB (Facility for Low Energy Experiments in Buildings) [17].”

Developing and test-bedding new sustainable building technologies from university researchers and industry partnerships is the purpose of the facility, but at the core of the project is an integrated approach to connect technology development to both economic and governance feasibility and development. As a first point, these types of projects in Singapore are part of visible, publicly legitimized, and government supported sustainable building initiatives, including the way they share and showcases new developments, products, and building processes.

The industry and collaborative aspects are examples of a process ${ }^{5}$ to facilitate commercialization and market development coincident with technology development phases [18]. But further, projects are now being created that include policy and law researchers to consider from early stages requirements for new legislation, institutional capacity, or rules needed for eventual technology adoption and successful project implementation [18]. Singapore is creating fully integrated and connected approaches, including input from and feedback into law, policy, and planning, for its sustainable building programs.

The advantage of a model like the three pillars is thoroughness, routinization, and speed in analyzing, developing, and successfully deploying sustainability solutions. Focusing on the implementation of sustainability solutions makes the use of three pillars framework particularly relevant, because it draws from evidence and practice in defining key parameters that have worked for a wide variety of applied and successful projects.

\subsubsection{For Public Policy to Achieve Sustainability Objectives}

Given the critical nature of the sustainability challenge now before us, improving public policy consists of fully and frequently considering sustainability issues across the full (and usually connected) range of our social and economic activi${ }^{5}$ See Reference [18] at page 7: to "tightly couple research with translation to market for widespread adoption of energy efficient solutions and practices, as well as streamline, coordinate and disseminate building energy efficiency related activities through a central focal point". 
ties. The three pillars strategy framework is a good guide here, too, for shaping many of the key levers of governance. The sections below that discuss the scope and scale of law are also relevant here, but to start it's more directly an extension from the project level in terms of broader social planning and goals.

One such priority for governments attaches immediately to providing education, which in turn plays many roles simultaneously with respect to sustainability. Universities shape the students and leaders of tomorrow. Sustainability needs to be integrated into the high-level skill sets on which our economies (that should, themselves, be increasingly and more closely attached to sustainability objectives and ecological boundaries) rely. If we are increasingly living on our wits to ensure our future survival, those wits need to be attuned to sustainability. Education at all levels contributes to an informed and responsible populace, able to consider multiple social goals (including sustainability) in their daily lives and when choosing their leaders. Sustainability isn't only a discipline, or even a field, it's also our most important global and social objective. It happens to contain all disciplines and fields, however, just as it affects all people and nations.

\section{Example 6. Sustainability education at NTU Singapore.}

Nanyang Technological University's online sustainability course (GC0001: Introduction to Sustainability, Multidisciplinary Approaches and Solutions) was introduced in 2014 as a project created and managed by NTU's Sustainable Earth Office (SEO), and has run every year since then. It's mandatory for all entering first year students (nearly 6000 every year) to be completed during their first year of studies. In addition to providing a common foundation in sustainability, and for motivating and exciting students, the three pillars framework was influential in creating the content to introduce and connect key topics related to technology, laws and governance, and economic markets. Several traditional disciplines and Schools, alongside translational research centers, created the modules:

Module 1 Sustainability and Earth, Environmental and Ecological Systems

(Earth Observatory of Singapore-EOS)

Module 2 Sustainable Energy

(Energy Research Institute @ NTU-ERI@N)

Module 3 Prosperity and Economic Growth within Ecological Boundaries

(Division of Economics-HSS)

Module 4 Sustainable Water Management, Urban Infrastructure, Built Environment

(Nanyang Environment and Water Research Institute-NEWRI)

Module 5 Sustainable Business, and the Role of Finance and Incentives

(Nanyang Business School-NBS)

Module 6 The Political Economy of Sustainability

(S. Rajaratnam School of International Studies-RSIS)

Given the world's rapid pace of urbanization, sustainability policy and planning is now more important than ever for cities, relating in particular to law and policy at regional and local levels. Admittedly, the transboundary and global nature of pollution problems can limit the effectiveness of many local solutions, but local and city levels of operation may produce more successful and consistent outcomes, and are also capable of influencing global points of pressure and 
stress. Or, if you prefer, cities are increasingly and often on their own to deal with environmental impact challenges, including adaptation challenges from climate change and sea-level rise.

However, today's sustainability challenges allow decreasing degrees of freedom for planning in most important areas of public activity, and issues from health care delivery, to immigration policy, to transport, to major infrastructure development projects should become part of policy-making for sustainability planning, and not the other way around. Put another way, the time when we could address individual problems individually, by optimizing solutions in isolation from other systems, is gone. Buffers and margins for error are also gone, and this is particularly evident in cities, where hard constraints, available space, and options require us to take a more integrated and systems oriented approach. The three pillars strategy framework represents this idea, both with respect to key elements required for sustainability solutions, but also as a framework to initiate planning and policy-making approaches.

Example 7. Singapore's wicked problems of population and sustainable development.

Singapore, like most global cities, is now facing a series of tough economic and political choices regarding economic growth, population pressure, immigration policies, and sustainable development. On the one hand, Singapore has for decades been an international talent attraction magnet. This importation and transfer of new ideas, thinking, and innovations has been a successful economic strategy. At the same time, Singapore has imported for nearly 30 years less-skilled foreign workers (to work in constructions, the retail service industry, and childcare, among other areas). The nation has clearly benefited economically from this balanced strategy of importing high and low-skill workers. Both of these strategies, however, create sustainability challenges.

Specifically, discussions on sustainability and cities must include issues of population growth (or shrinkage) and demographic challenges like aging populations (or youth bulges, low domestic birth rates, and brain drain), and these are key issues for Singapore. Approximately 1.7 million of Singapore's 5.5 million inhabitants are non-residents (more than 30\%). Following recent trends in growth and immigration, Singapore's population would be expected to rise to nearly 7 million people by 2030 [19]. About 60 percent of this planned demographic growth is expected to come from non-residents. Such perspectives raise questions about the future of the city which already is felt to be space limited and in the midst of all the expected cultural transitions associated with substantial immigration.

As such, questions about population and demographics are being debated here in a community that has deeply embedded expectations about annual GDP growth and high levels of personal consumption. Recent surveys of Singaporean voters reveal the following concerns: 1) stable and reliable economic opportunities for future generations; 2) increased capacity and less crowded transportation systems for subways and highways; 3) decreased housing availability and increasing housing prices; 4) social stresses and over-crowding caused by immigration; and 5) steadily rising prices of consumer goods, but also of staples such as food, energy, and water. Importantly, sustainable economic development is at the inter-connected heart of all of these voter issues.

Singapore has been actively working to address these concerns through sustainability planning and blueprints [20]. And in Singapore, as in many large cities throughout the world, the constraints are starting to bind, in terms of space and capacity, but also politically. For instance, as immigration has been limited, economic performance and growth 
in some sectors has already suffered. But to return to immigration at previous rates would be both socially stressful and would pressure housing, transport, and other infrastructure requirements that are already constrained.

Singapore's way forward out of wicked problems like this is to frame sustainable development as an economic opportunity: in technology development, as well as in management systems and services; but, also in terms of establishing future economic growth more upon productivity increases and innovation potential than on growing populations (labor inputs) or infrastructure (as necessary responses to expanding populations). By connecting key inputs of technology, laws and governance, and economic drivers for major sustainability projects, as well as developing the supporting governance and institutional capacity, Singapore is following a template similar to that described by the three pillars strategy framework.

As a final point here, public policy and law also play powerful normalizing and legitimizing roles in society. They are typically most successful not only as top-down mandates, but in their roles as part of, and often responding to, larger social dynamics that include culture and public opinion. In a less linear way, then, but often as a key response to political necessity, or sometimes themselves drivers and nudging influences, laws play an influential social and cultural role beyond their immediate deterrents and incentives. Given the serious and increasingly binding nature of our ecological hard constraints, we observe these basic relationships operating (in all directions at once), driving forward, and demanding responses for more sustainable development (Figure 6).

\subsubsection{For Establishing Research and Funding Priorities}

Research agendas and funding of research are also part of public policy, and this is connected to or driven from other stakeholders and market actors. As an initial matter, starting with planning for society's sustainability priorities helps determine where, and from whom, research and solutions are most needed. Universities and corporations together lead in advancing research, creating new markets, and making technological break throughs. This describes neatly the inter-connectedness that needs to be considered for multi-stakeholder and multidisciplinary sustainability (Figure 7).

The fact is that multidisciplinary research, collaboration, and cooperation are difficult, and always have been. In precisely the sense emphasized previously, it often requires the sub-optimization of individual inputs (less engineering of solutions, or less economic optimization) in order to optimize the whole (defined here as successful sustainable development solutions at the speed and scale required). The three pillars framework also imposes a certain amount of discipline on sustainability research agendas and projects because a balanced and transdisciplinary approach needs to be considered and incorporated at many stages and time frames.

The multidisciplinary aspects of this are important in terms of bringing together the different disciplines and skills required, but establishing a foundation for multidisciplinary and transdisciplinary work is even more important. This emphasizes the need in setting (and then reconsidering and resetting) research 


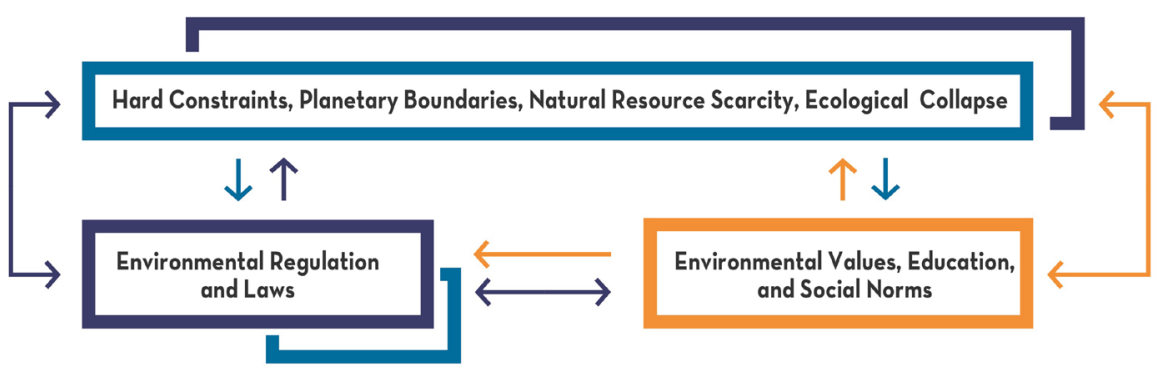

Figure 6. Laws and governance are part of a dynamic process driven by (and in turn affecting) sustainability challenges and ecological crises, as well as by evolving cultural norms and values which both drive new laws and are determined or influenced by existing laws.

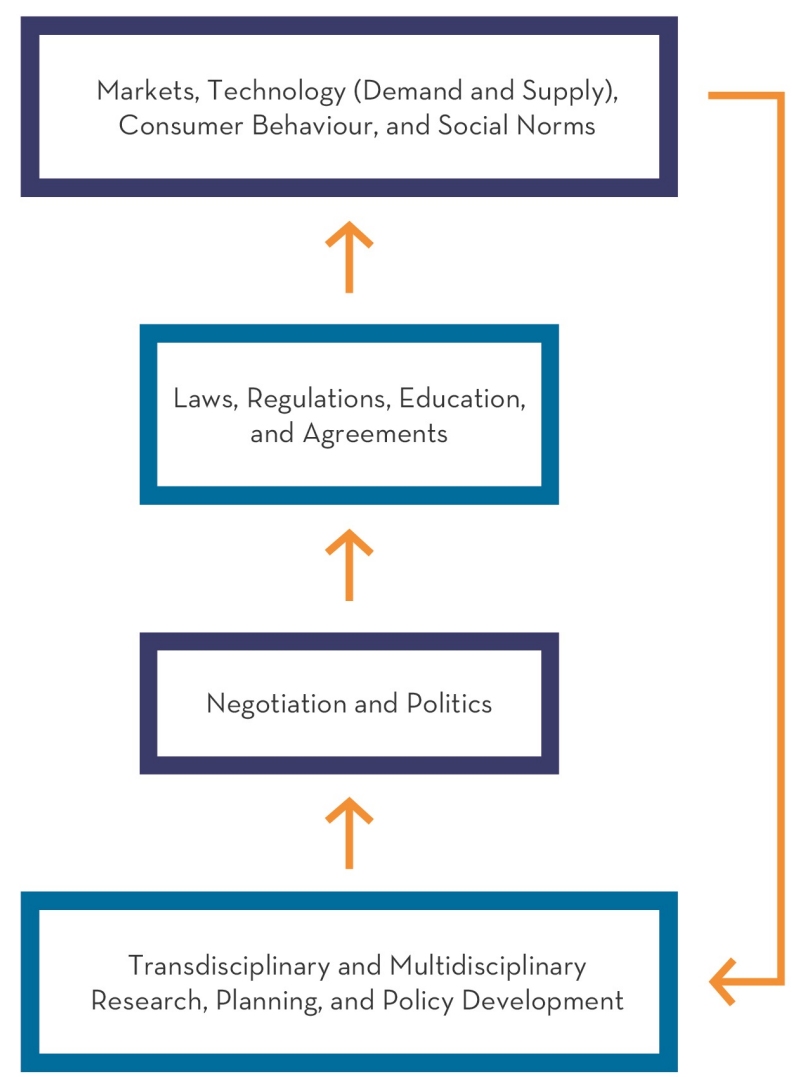

Figure 7. Determining sustainability research agendas and funding should be considered within the context of dynamic public policy, cultural, and economic processes.

agendas for a flexible approach and paradigm, as much as one able to assemble all the necessary inputs. In other words, complex problems (like sustainability) are highly dynamic, with emergent properties, and require a flexible research and learning approach. Being supported and built around a framework like the three pillars model is still helpful here, because any changes in research need and priorities will still require inputs and disciplinary support from technological, legal, and economic areas. 
Of course, research and applied work are closely related (which accounts for the success, for example, of many academic and corporate collaborations, as well as the proliferation of translational research centers and joint test-bed and laboratory facilities). The three pillars model directs both activities in a generally positive trajectory by accounting for feasibility, opportunity, and success for all of the key stakeholders. For example, as suggested above, early consideration of economic feasibility and legal requirements are beneficial to and supportive of sustainability research and technology development if success in implementation and commercialization are among the objectives.

Further, sustainability research priorities can be based upon areas of known or developing market failures. In other words, if we accept from a framework like the three pillars model that we'll need economic markets to engage in order to implement new technologies or solutions, then this often indicates immediate roles for government support or action. But it also suggests the need for new research support from economic or legal disciplines. And, further, it's often helpful to create an integrated connection back to technology development in cases where newly identified economic or legal inputs indicate previously unconsidered obstacles or opportunities for technology and innovation.

Example 8. Market failures, urban transportation, and path dependency.

The example represented in this chart shows the possibility that beneficial long term mass transit options won't be part of growing cities or urban communities, because the economics so favor cars and busses at early stages (until reaching a critical threshold of ridership). Why don't markets quickly embed these time horizons and present profitable opportunities for investment (now) and profitable revenue streams (in the future)? Part of the answer may be the lack of full financial intermediation in sustainability markets and products compared to more traditional financial products and services markets. Nevertheless, and for purposes here, this can be categorized as a market failure.

\section{Average Cost of Alternative Transportation Systems}

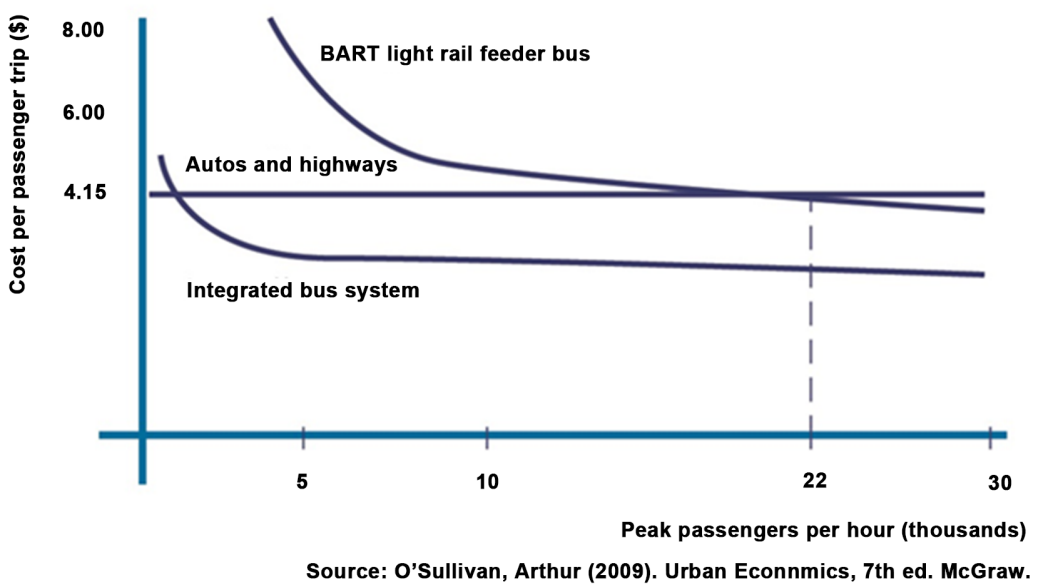

The average cost of an automobile system is constant, but the average cost of a bus system or light rail (BART) decreases as the volume of users increases. 
In this example, without government support, or other ideas for addressing the missing pillar of early economic feasibility of more efficient and sustainable transport options, we risk following the least best transport option. In fact, this can become an expensive problem to reverse later if we wanted to switch transport options after investing heavily in another choice. Clearly, the connection between society's sustainability goals and setting our priority research agendas is important here, based first upon the primary goal of achieving sustainable development at scale and speed, and based upon approaches like the three pillars framework to help us identify critical break points or opportunities.

This is also a perfect example, however, of needing as much design work as we need planning, in the sense that over-planning is also a risk compared to a more flexible (and update-oriented) structure. The same path dependency just mentioned that can lead to lock-in to suboptimal vehicle transport choices compared to mass transit options, can operate in other ways.

For example, we can also be locked-in to technology choices that were right at the time they were first considered, but become poor choices as other sustainability and development issues begin to bind or become relevant. The three pillars model to address sustainable development challenges speaks as much to flexible (but supported) approaches as to specific project implementations. Consider, for example, an extension of the basic transportation question:

"Apart from optimizing the present system, however, we know that the total system, as well as the individual transport modalities, are directly connected to hard constraints related to sustainability, such as land use, energy security, and pollution, as well as to other trade-offs that inevitably must be made when the future transportation system is shaped. And policies driven only by technological advancement often lead to problems if the interconnections with social, economic, and governance issues are not taken into account.

Suppose the decision is made to introduce electric vehicles to decrease local pollution, dependence on oil, and carbon dioxide emissions. Such a decision comes with a commitment to promote the vehicle modality (as opposed, perhaps, to shifting to mass transit), which in turn is a commitment to the related creation and maintenance of road infrastructure (which requires land and other resources). Also, it may require a new energy supply, ways to deliver it, and new infrastructure to provide re-charging possibilities.

And these decisions will affect many aspects of social life, such as preferences for housing, need for parking lots (more space), estate development, real-estate pricing, road congestion, commute times, and choices for employment location. In fact, the transportation system is connected to many major aspects of public wellbeing. Consider public health: pollution influences diseases like asthma and childhood pulmonary development issues; traffic jams and long commutes relate to stress and depression; and of increasing importance will be relationships to elder care and ease of access to hospitals [21].”

In summary, electric vehicles, as well as funding their research and development, may well be a good choice for modern and urban transport solutions, but their deployment is something we must analyze and test in the context of the complex web of other options and ongoing technological relationships. As a final extension of this example, with the development of driverless vehicles we may be reaching a point of new convergence where individual electric cars could become part of chains of (autonomous agent) vehicles operating within a computer-assisted stream of traffic. What started, in other words, as a relatively inefficient automobile transport model, may start to resemble many other mass transit options.

\subsubsection{Matching the Scope and Scale of Laws and Governance to Ecological Challenges}

We live in an economically, transdisciplinary, and globally integrated world, 
with respect to our biggest environmental impact challenges, with regards to accelerating global urbanization, and with respect to our need for the rapid creation and implementation at scale of sustainability solutions. To effectively address the integrated nature of sustainability requires the simultaneous participation and coordinated support of many institutions, stakeholders, disciplines, socio-economic levels, and geographical scales of operation.

In this, the potential impact and necessary coordination role for law and legal processes is obvious. Scholarship and projects emphasizing the need to match the scope and scale of law to our planetary boundaries and the ecological challenges of sustainability are certainly on target [22]. This has always been a matter of matching regulatory and incentive structures to ecological boundaries (like watersheds), and not just political boundaries. It's also about better coordination between local, regional, and international law and governance structures: which too often still invoke legal support or authority from sources that can provide little, or that fail to coordinate major gaps or loopholes [22].

Another approach focuses on local law, and is particularly appropriate considering global urbanization trends and the increasingly important role of cities in leading sustainable development:

"Yet, environmental law and governance comprise different levels and scales (planetary, continental, regional, local etc.) simultaneously. Regardless of geographical scope, the possible agreed measures, cooperation, policies and legal frameworks must be anchored and implemented locally, so as to influence the conduct of individuals, for instance with respect to the introduction of greenhouse gases, use of energy and food habits. Put together, national and local laws are therefore critical for the possibility of implementing global accords so as to avoid international environmental problems [22]."

What the three pillars of sustainability strategy framework can contribute here is a supportive refinement that is particularly strong at the local and city level. The model addresses project- and implementation-level sustainability solutions: in this, consideration of the key elements that will be needed (within some degree of balance, or with consideration of strengthening the weakest link) produces more successful sustainability outcomes that will empower and increase the effectiveness of the people and parties being asked to implement global and international environmental accords. In a similar way, but in a more general screening capacity, the three pillars could be used as a baseline or litmus test in the examination (or re-examination) of many of society's current legal processes, governance structures, and regulatory baselines, as well as for assessing institutional capacity to support sustainable development.

At the same time, the applicability of the three pillars often scales up to other levels of law and governance (from city to regional, for planning purposes, policy making, regarding fundamental market operations, and from national to international scales). The consideration of coordination gaps, for instance, between national and international law frameworks could often be improved further by ensuring that key elements are in place (technology, governance, and 
law) at the most appropriate operational levels to allow functioning solutions to develop. In fact, this is very much in keeping with the notion of flexible but guided objectives ${ }^{6}$ to improve effectiveness and coordination [22].

\subsubsection{For Supporting Legal Decision-Making}

Finally, the preceding sections begin to suggest another use of the three pillars model for law and governance as a support for legal decision-making in a variety of contexts. Such an application for judicial and legal decision-making is based upon the fact the model relates to, and helps ensure, applied sustainability solutions. For example, referring again to the Preussen Elektra case, using the three pillars framework we could be more confident that Germany's economic decision to support its domestic renewable energy industry was based primarily not upon arbitrary or contrived excuses for self-enrichment (at the expense of undertakings from other nations), but upon a proven template for establishing and implementing sustainability projects. This approach could prove useful for legal consideration and balancing of competing priorities (including those related to economic and market protections). Put another way, theoretical applications of sustainable development warrant less consideration compared to projects and planning following steps likely to lead to implementation and success.

This can probably be extended further, however, based on the increasing and explicit need for balancing sustainability and economic objectives in many constitutional systems, constitution-like systems (e.g. the Treaty of Lisbon), and regional international agreements (like the ASEAN Charter). Article 6, for example, of the TEU represented a genuine paradigm shift within Union law [23]. While the European Court of Justice previously developed fundamental human rights doctrines, they are now established as foundational principles in the Treaty of Lisbon, itself, equivalent to all other provisions including economic and internal market objectives. Specifically, Article 6 TEU's recognition of the Charter of Fundamental Rights (“CFR”) includes environmental protection: “A high level of environmental protection and the improvement of the quality of the environment must be integrated into the policies of the Union and ensured in accordance with the principle of sustainable development [24]". In fact, the Treaty of Lisbon expands on concepts of sustainability found in previous treaties requiring a balance of social, economic, and environmental dimensions. ${ }^{7}$

At the same time, environmental protection is not an Article 36 derogation

${ }^{6}$ See Reference [22] at 283-284: "While some such steps have been taken already (e.g. among regimes concerning chemicals, biodiversity and marine pollutants), coordination and cooperation will have to be further developed and intensified between international regimes of different scales; and in this process, international and national environmental laws will also have to be further integrated. Although the suggested boundary themes as well as the actual boundaries suggested are uncertain, increased attention to the notion of planetary boundaries may improve international cooperation, coordination of treaty regimes and normative integration, and thereby make international law more effective".

${ }^{7}$ See Article 3.3 TEU (The Union "shall work for the sustainable development of Europe based on balanced economic growth and price stability, a highly competitive social market economy, aiming at full employment and social progress, and a high level of protection and improvement of the quality of the environment"). 
permitting restrictions of economic free movement, but it is one of the many legitimate public policy exceptions known as "mandatory requirements" that may be applicable. ${ }^{8}$ In considering the application of mandatory requirements, the Court applies proportionality, its principle balancing test, to ask if public policy exceptions are proportionate to their claimed objectives when balanced against proposed restrictions to economic and free movement doctrines. ${ }^{9}$ In fact, the European Court of Justice has (over the last 25 years) increasingly applied proportionality in determining that restrictions on economic free movement may be justified by legitimate state environmental objectives [25]. In this, the three pillars of sustainability strategy framework may offer a pragmatic refinement to help determine whether claimed public policy exceptions are legitimate or likely to lead to successful project or policy outcomes.

In fact, these basic arrangement and relationships are similar in the Association of Southeast Asian Nations (ASEAN) Charter [26]. Obviously, there are significant differences (advantages and disadvantages) between a constitutional system like the United States (with a federal supremacy clause and a Supreme Court), the Treaty of Lisbon for the EU (which is not a constitution, has no explicit supremacy clause, but does have a European Court of Justice), and the ASEAN Charter (consensus politics, a high degree of national autonomy, and no central court). Nevertheless, many of the balancing considerations we're now considering, whether in law or negotiation, turn on similar considerations.

Consider ASEAN's economic function as a regional peace (through economic and cultural integration) and prosperity project:

"To create a single market and production base which is stable, prosperous, highly competitive and economically integrated with effective facilitation for trade and investment in which there is free flow of goods, services and investment; facilitated movement of business persons, professionals, talents and labour; and freer flow of capital [26]."

And compare this to ASEAN's strong commitment to sustainable development:

"To promote sustainable development so as to ensure the protection of the region's environment, the sustainability of its natural resources, the preservation of its cultural heritage and the high quality of life of its peoples [26]."

"RESOLVED to ensure sustainable development for the benefit of present and future generations and to place the well-being, livelihood and welfare of the peoples at the centre of the ASEAN community building process [26]."

Consider again the example of fundamental human rights, which would mean relatively little unless legal provisions granting equal access, human dignity, and due process carried through to results, including adequate consideration in law and process, as well as the establishment of consistent practices in everyday life. Sustainable development and environmental protection are also now funda${ }^{8}$ These mandatory requirements are created by court law as categories of derogations. See Reference [25].

${ }^{9}$ See Article 5 TEU. 
mental determinants of human dignity, opportunity, prosperity, and survival. It's the reason, in fact, that strong sustainability goals have increasingly prominent places as constitutional objectives.

But, as social goals and case law have developed in the EU and elsewhere, it's no longer simply a matter of proposing stronger consideration for sustainability exceptions when balanced against economic objectives and the creation of internal markets (which continue to legitimately represent their own important objectives, including for peace and cultural integration). On the one hand, as the three pillars model makes clear, sustainability and economic viability are actually closely connected, and a more integrated analysis would be even more useful.

In this way, and more like the cases about fundamental human rights, our sustainability goals and laws don't mean much unless they are also translated into action (at speed and scale) through and within our legal processes and institutions, themselves. The three pillars framework for sustainability provides one possibility, whether as a refinement to existing legal balancing tests, or as a litmus test used in adjudicatory or legal proceedings. It may help define the legitimacy or viability of given policies or projects by simultaneously considering key national objectives (technology and innovation goals; economics objectives; and through the institutions of laws and governance) within a pragmatic, implementation and solutions oriented strategic framework.

Example 9. Green procurement in the EU, and balancing economic objectives.

There are many potential sustainability and environmental advantages (not the least of which is reducing transport distances and fuel use) to using local suppliers and sources for government or corporate procurement. In the EU (and other places) there is often a tension between federal economic goals and state procurement and environmental objectives, related primarily in the European context to prohibitions against state aid or in discriminatory laws and practices that economically favor domestic undertakings [27].

In addition to many direct environmental benefits, however, procurement practices are often related to more extensive national sustainability projects:

"State procurement goals may involve reducing environmental impacts from purchases, such as requiring public power generation utilities to purchase less polluting fuels. But green procurement is just as likely to involve incentivizing the growth of private green industries, such as linking public fuel purchases to specific renewable energy-producing sectors. And green procurement is equally about influencing the environmental behaviours of private market actors, such as mandating waste recycling and then building collection networks and facilities that permit or preference certain types of materials. Simply put, a state purchase of goods or services may, itself, be the environmental goal, but may, increasingly, be a means to other environmental goals [27]."

Even in the context of increasingly important EU sustainability and environmental objectives, economic free movement protections remain of primary importance. In an example such as green procurement, incorporating a broader, more generally applicable, understanding of the support pillars of sustainability solutions frames the discussion in a new way. We can't ignore the elements that permit the successful implementation of sustainability projects. And, likewise, economic success and development will increasingly be driven by markets for cleantech, renewable energy, environmental conservation solutions, and sustainability-related technology and products. 
Actually, there's already a convergence happening in EU law. Consider, for example, block exemptions ("GBER") that exempt many kinds of "environmental investment aid for the promotion of energy from renewable energy sources" and "aid for environmental studies" that might otherwise be considered to violate commercial or competition law [28]. And with respect to green procurement, the GBER goes further in endorsing "the acquisition of new transport vehicles enabling undertakings active in the transport sector to go beyond Community standards for environmental protection [28]". As such, EU economic objectives may become more directly relevant for supporting sustainability projects if they are consistent with EU economic priorities for increasing innovation and developing new economic markets.

In other words, the sustainability paradigm, including "doing more with less" in order to position economic production and consumer demand within planetary and ecological boundaries means that many of the former divisions are breaking down between economic and sustainability opportunities. Member state legal measures, rule-making, and governance in support of green procurement may be less about the initiation of discriminatory national projects, and more about supporting or removing bottle-necks to otherwise innovative and economically forward looking sustainability practices. In this, a more integrated approach to legal balancing tests may be useful, including one like the three pillars framework that puts into focus key elements for considering EU economic objectives as part of sustainability objectives.

\section{Conclusions}

The three pillars of sustainability framework is solutions oriented because nearly all sustainability projects that are successful and scalable are driven by all three pillars simultaneously (technology and innovation; laws and governance; and economics and financial incentives). This approach is useful for a sustainability field that is complex, multidisciplinary, fully integrated, and that now needs to be implemented rapidly and at scale if we are to avoid many of the worst environmental impact and climate change scenarios.

The three pillars framework focuses on cutting edge stages of research, multi-stakeholder collaboration, and sustainability projects, and can be used at different scales as a template to analyze break points, define and shape possible solutions, and identify missing inputs and stakeholders. In this, it's also useful as a template to guide public policy creation, shape governance structures, and support legal decision-making, particularly related to matching the scope and scale of law to our sustainability challenges.

That said, it's anything but straight forward to describe the multitude of flexible forms, approaches, processes, or entry points that a successful solutions path for a sustainability challenge could take. This challenge is primarily due to the fact that there are different entry points and disciplines, and multiple levels of institutional support, involved in successful sustainability projects. On one hand, we could look at technology and economic markets as the actionable end points of our sustainability goals, operating autonomously, but also interacting with politics and laws.

The centrality of markets to this process explains the importance of economics, and the importance of technology explains the importance of the natural science, engineering, and university research. On the other hand, the cutting 
edge of sustainability solutions may not be technological development, because the last, critical, creative, and often most innovative stage may be the implementation of laws, legislation, regulation, compacts, and agreements. These are based on prior stages of scientific knowledge, but are themselves the softest disciplinary set.

Creating agreements, developing compacts, and enacting and enforcing regulations involve all the social sciences, as well as the crafts and nuances of persuasion and negotiation. Included here is the importance of specific local contexts, self organization, path dependency (how prior status influences later possibilities), diplomacy, and so on. And throughout all of it, is an analysis of cultural change (including tipping points) and political resistance.

If this is frustrating to scientists and engineers, it's also frustrating to law and policy makers; and we all may, or may not, be comforted by the fact we're stuck together within this complex, integrated, systems-oriented sustainability challenge. The three pillars of sustainability strategy framework, in addition to being practical and project focused, emphasizes an integrated and connected approach to thinking about sustainability outcomes and institutional processes.

Flexibility is part of the model, too, in creating a (minimally intrusive) support structure that emphasizes key inputs and elements, but leaves open questions of proportion, order, entry point, or configuration. Ultimately, it doesn't matter which direction(s) the solution path follows. What's clear is that we need to act quickly, at scale, and by introducing some deep changes into all of society's normal operations and processes to develop and deploy effective, practical, and successful sustainability solutions.

\section{References}

[1] Knud-Hansen, C. (1994) Historical Perspective of the Phosphate Detergent Conflict. Working Paper, Conflict Research Consortium. University of Colorado, Boulder, Colorado.

[2] EU Environmental Directorate (2002) Final Report, Phosphates and Alternative Detergent Builders. EU Environmental Directorate, Brussels.

[3] Rockström, J. (2009) Planetary Boundaries: Exploring the Safe Operating Space for Humanity. Stockholm Resilience Centre. Ecology and Society, 14, Art 32. https://doi.org/10.5751/ES-03180-140232

[4] European Union Law (2001) Preussen Elektra AG \& Schleswag AG, C-379/98.

[5] Adolphson, U. (2010) Article 102 TFEU, Aimed at Serving the Ordoliberal Agenda or European Consumers? Uppsala Universitet, Uppsala.

[6] Sommer, J. (2013) Getting Creative with the G.D.P. New York Times.

[7] Hausmann, R. (2014) The Mismeasure of Technology. Project Syndicate.

[8] Hausmann, R., Pritchett, L. and Rodrik, D. (2005) Growth Accelerations. Harvard Kennedy School, Cambridge.

[9] The Straits Times (2017) 20 February 2017, Singapore.

[10] Civil Service College (2014) Liveable and Sustainable Cities: A Framework. Centre for Liveable Cities and Civil Service College, Singapore. 
[11] National Climate Change Strategy (2012) Climate Change \& Singapore: Challenges. Opportunities. Partnerships. National Climate Change Secretariat, Singapore.

[12] Ministry of the Environment and Water Resources and Ministry of National Development (2009) A Lively and Liveable Singapore: Strategies for Sustainable Growth. Ministry of the Environment and Water Resources and Ministry of National Development, Singapore.

[13] US Energy Information Administration (2017) https://www.eia.gov

[14] Clune, W. and Braden, J. (2007) Financial, Economic, and Institutional Barriers to Green Urban Development. IWA Publishing, London.

[15] San Diego Municipal Code (2017) City of San Diego, Land Development Code $\$ 143.0920$.

[16] City of San Diego (2014) Mixed-Use Urban Villages: Key Zoning Code Issues and Options. Public Discussion Draft.

[17] Singapore Building and Construction Authority (2017) Skylab. https://www.bca.gov.sg/skylab/

[18] Singapore Building and Construction Authority (2014) 3rd Green Building Masterplan. Singapore Building and Construction Authority, Singapore.

[19] Singapore Government (2013) A Sustainable Population for a Dynamic Singapore: Population White Paper. Singapore.

[20] Ministry of Environment \& Water Resources (2015) Our Home, Our Environment, Our Future: Sustainable Singapore Blueprint. Singapore.

[21] Vasbinder, J., Clune, W., et al (2013) The NTU White Paper on Sustainable Cities. Report of Multidisciplinary Working Group Developing a Singapore-Based Research Approach to Developing Better Questions for the Complex Problems of Sustainability and Resilience in Cities. Unpublished.

[22] Ebbesson, J. (2014) Planetary Boundaries and the Matching of International Treaty Regimes. Scandinavian Studies in Law, Volume 59.

[23] European Union (2007) The Treaty of Lisbon. Signed 13 December, 2007, Entered into Force 1 December, 2009, Including Both the Treaty on European Union (TEU) and the Treaty of the Functioning of the European Union (TFEU).

[24] European Union (2007) Charter of Fundamental Rights of the European Union, 2007/C 303/01.

[25] Eugen Schmidberger (2003) Internationale Transporte und Planzüge v. Republik Österreich, Case C-112/00, 2.

[26] ASEAN (2008) The Charter of the Association of Southeast Asian Nations, ASEAN. Entered into Force on 15 December 2008.

[27] Clune, W. (2011) A Comparative Law Analysis of the Use of State-Level Green Procurement in the European Union and the United States. Nordisk Miljörättslig Tidskrift/Nordic Environmental Law J, December.

[28] European Union (2008) General Block Exemption Regulation for State Aid, Reg No 800/2008, European Union Law. 